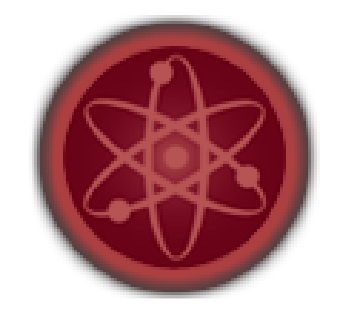

\title{
JOURNALRU
}

Шутикова М.И. ${ }^{1}$, Смирнова Е.А. ${ }^{2}$, Лягинова О. Ю. ${ }^{2}$

${ }^{I}$ ГБОУ ВО МО «Академия соииильного управления»

Россия, Москва

${ }^{2}$ ФББОУ ВПО «Череповецкий государственный университет»

Россия, Череповеи

doi: 10.18411/1j2016-2-31

\section{Предметно-ориентированные пакеты программ в процессе формирования компетенций}

Основными целевыми ориентирами в реализации ФГОС ВО третьего поколения являются компетенции, полученные учащимся в процессе обучения. Под термином «компетенция» понимается способность применять знания, умения, навыки и личностные качества для успешной профессиональной деятельности в определенной области. Многогранное понятие компетенции включает личностные качества: инициативность, целеустремленность, ответственность, толерантность и социальную адаптацию - умение работать как самостоятельно, так и в коллективе, и профессиональный опыт. Вышеназванные совокупности формируют деятельностные модели - когда выпускник способен самостоятельно ориентироваться в ситуации и квалифицированно решать стоящие перед ним профессиональные задачи. Компетентностный подход предусматривает активную деятельность студента в учебном процессе, в основе, которой лежит работа с информацией, проектирование, моделирование, рефлексия.

Область профессиональной деятельности бакалавров включает научноисследовательскую, проектную, производственно-технологическую, 
организационно-управленческую и педагогическую работу, связанную с использованием методов математики, программирования, информационнокоммуникационных технологий и автоматизированных системам управления.

В учебных планах по направлению прикладная математика и информатика присутствует весомая доля дисциплин информационного цикла, что вполне обосновано для современного информационного общества, в котором основным видом деятельности является информационный, преобладающий над всеми остальными. Успешность освоения дисциплин данного цикла во много связана с формированием профессиональных компетенций. Рабочая программа дисциплины (модуля) «Программирование» включает компетенции ПК-5 и ПК7, формируемые в результате освоения модуля. Компоненты формируемых компетенций (ПК-5) - это и знания о возможностях ресурсов и сервисов Интернета в области программирования и умения использовать поисковый сервис для получения информации в области программирования; использовать сетевые ресурсы для разработки программного обеспечения. А так же владение навыками разработки программ с использованием сетевых ресурсов. Компоненты формируемых компетенций (ПК-7) - это теоретические значения в области программирования и умение разрабатывать программу с использованием выбранного языка/системы программирования; осуществлять отладку и тестирование программы, и владение навыками использования полученных знаний при решении задач.

При изучении дисциплины «Мультимедийные технологии» формируется компетенция ПК-6. Компоненты формируемой компетенции - знание этапов разработки проекта мультимедиа, инструментальных средств авторских систем мультимедиа, а так же умение использовать технологии мультимедиа для создания, обработки и компоновки стандартных форматов файлов текстовой, графической, звуковой, видео информации. В результате изучения дисциплины у обучающихся должны быть сформированы навыки создания мультимедиаприложений для профессиональной деятельности на примерах разработки 
статических и динамических сценариях индивидуальных мультимедиапроектов. Составим таблицу 1 соответствия формируемых компетенций и изучаемых дисциплин.

Таблица 1

\begin{tabular}{|l|l|}
\hline Компетенция & \multicolumn{1}{|c|}{ Дисциплина } \\
\hline ПК-1 & «Теория игр и исследование операций», \\
\hline ПК-2 & $\begin{array}{l}\text { «Теория игр и исследование операций», «Методы криптографии и защиты } \\
\text { информации» }\end{array}$ \\
\hline ПК-3 & $\begin{array}{l}\text { «Теория игр и исследование операций», «Системы искусственного } \\
\text { интеллекта» }\end{array}$ \\
\hline ПК-4 & $\begin{array}{l}\text { «Системное и прикладное ПО», «Сетевые операционные системы», } \\
\text { «Корпоративные информационные системы», «Предметно-ориентированные } \\
\text { информационные системы» }\end{array}$ \\
\hline ПК-5 & $\begin{array}{l}\text { «Телекоммуникационные технологии», «Базы данных», «Безопасность } \\
\text { компьютерных систем », «Корпоративные информационные системы», } \\
\text { «Предметно-ориентированные информационные системы» }\end{array}$ \\
\hline ПК-6 & $\begin{array}{l}\text { «Технология электронного обучения», «Телекоммуникационные } \\
\text { технологии», «Мультимедийные технологии» }\end{array}$ \\
\hline ПК-7 & $\begin{array}{l}\text { «Базы данных», «Алгоритмы и алгоритмические языки», } \\
\text { «Программирование» }\end{array}$ \\
\hline
\end{tabular}

Из таблицы видно, что при изучении дисциплин информационного цикла по направлению прикладная математика и информатика все семь профессиональных компетенций будут сформированы.

Для формирования профессиональных компетенций необходимо применение различных подходов в обучении. В теории и практике преподавания дисциплин информационного цикла, сложился положительный опыт разработки и применения эффективных, практико-ориентированных подходов. К таким подходам следует отнести применение профессиональных пакетов программ для выполнения учебных задач с целью приобретения знаний и опыта в обучении, ориентированных на активное участие личности в процессе освоения, часто самостоятельном, теории, заданий, выполнение которых связано с предметно-ориентированными программными средами, такими как, IBM SPSS, 1C: Предприятие 8.0, Harvard Graphics и другие, способствующих профессиональной интеграции личности в современное, информационное общество. Данное программное обеспечение является частью информационной среды вуза, в системном представлении которой учебный процесс занимает 
важнейшее место. Модель организации учебного процесса в информационной среде вуза с использованием предметно-ориентированных пакетов прикладных программ представлена на рисунке 1 .

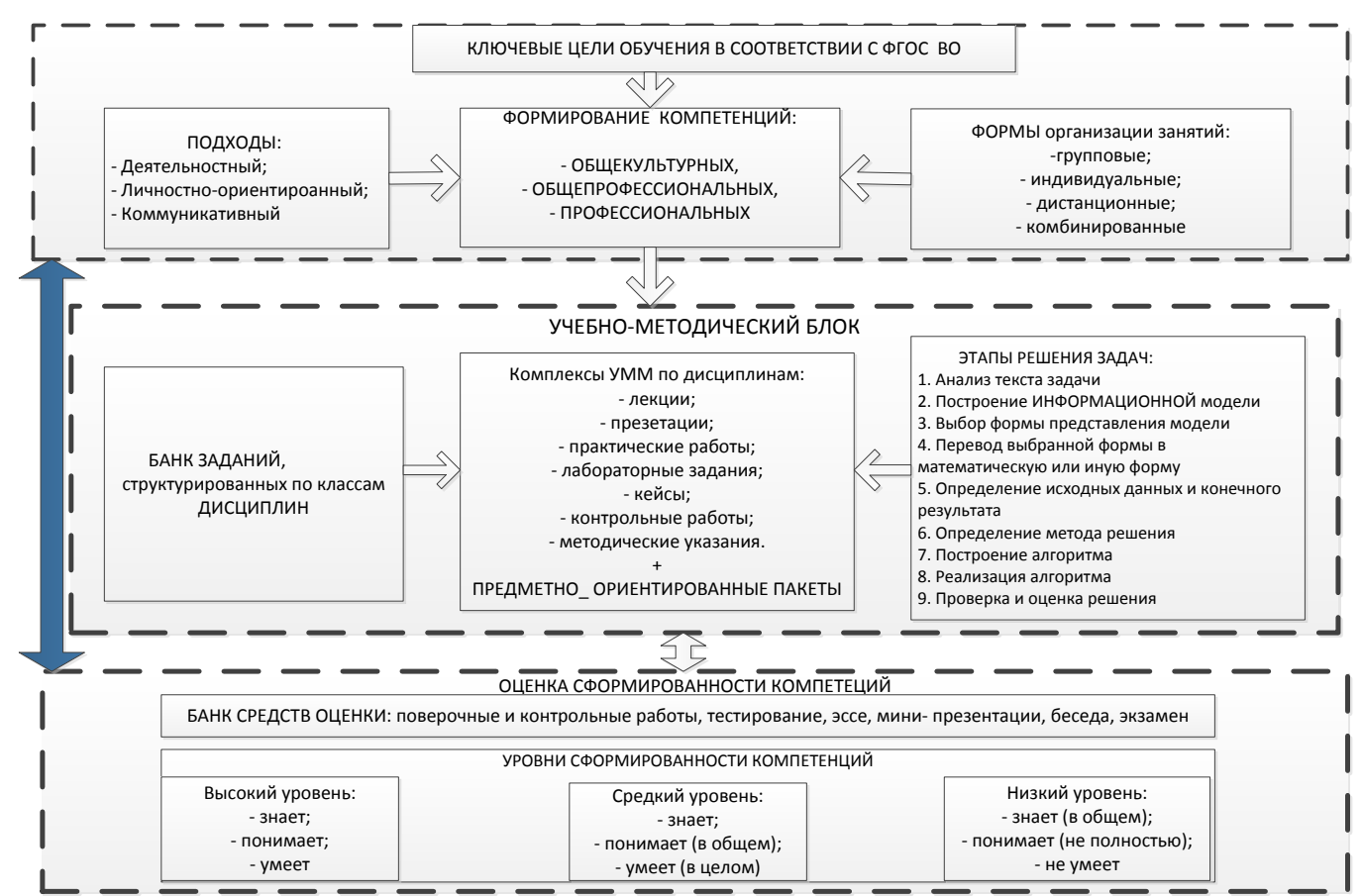

Рис. 1. - Модель организации учебного процесса в информационной среде вуза

Предлагаемая модель организации учебного процесса в информационной среде вуза позволяет решать задачи повышения качества подготовки специалистов за счет формирования банков материалов учебно-методического обеспечения, средств оценки уровня сформированности компетенций с применением предметно-ориентированных пакетов программ в процессе обучения. 


\section{Литература:}

1. Шутикова М.И. Организация учебного процесса в вузе на основе модульной системы. // Современные научные исследования. Выпуск 3. Т. 13 - Концепт. 2015. - c. 3941-3945. - ART 85789 URL: http://e-koncept.ru/2015/85789.htmISSN 2304-120X/ 